\title{
PARÂMETROS RUMINAIS DE VACAS LEITEIRAS MANTIDAS EM PASTAGEM TROPICAL
}

\author{
PARAMETERS OF RUMEN FERMENTATION OF DAIRY COWS GRAZING \\ TROPICALFORAGE
}

\author{
Mota, M.F. ${ }^{1}$, Vilela, D. ${ }^{2 A}$, Santos, G.T. dos ${ }^{3 *}$, Elyas, A.C.W. ${ }^{4}$, Lopes, F.C.F. ${ }^{2}$, \\ Verneque, R. da S. ${ }^{2}$, Paiva, P.C. de A. ${ }^{4}$ e Pinto Neto, A. ${ }^{1}$
}

${ }^{1}$ Faculdade de Medicina Veterinária. UNIPAR. Umuarama, PR. Brasil.

2Embrapa Gado de Leite. Brasil. Avilela@cnpgl.embrapa.br

${ }^{3}$ Departamento de Zootecnia. Universidade Estadual de Maringá (UEM). Campus Universitário. Av. Colombo, 5970. CEP 87020-900. Maringá, PR. Brasil. *gtsantos@uem.br

${ }^{4}$ Departamento de Zootecnia. UFLA. Lavras, MG. Brasil.

\section{PalaVRas chaVe adicionais}

Ácidos graxos voláteis. Coastcross. Pasto Bermuda. Cynodon dactylon. Produção de leite a pasto. Produção de ruminantes.

\section{RESUMO}

Foram utilizadas quatro vacas, portadoras de cânula no rúmen para estudar dois níveis de suplementação concentrada (base na matéria seca): 2,7 e 5,4 kg/vaca/dia, respectivamente, baixo $(B C)$ e alto concentrado (AC). As vacas foram mantidas em pastejo intermitente de capimCoastcross no período de verão, com lotação de cinco unidades animal/ha. O concentrado, para os dois níveis de suplementação apresentou a mesma composição química e foi dividido em partes iguais, fornecidas no momento das ordenhas da manhã e da tarde. Objetivou-se verificar efeitos do nível de suplementação com concentrado sobre o pH e as concentrações de nitrogênio amoniacal (N$\mathrm{NH}_{3}$ ) e de ácidos graxos voláteis (AGV) do rúmen. O Coastcross apresentou, em média, $11,7 \%$ de proteína bruta (PB); $70,2 \%$ de fibra em detergente neutro (FDN); $35,2 \%$ de fibra em detergente ácido (FDA) e $63,8 \%$ de digestibilidade in vitro da matéria seca (DIVMS). A ingestão total de alimentos foi, em média, de 13,4 e 14,6 kg de MS. A composição química das dietas ingeridas foi de 13,6 e 15,2\% de PB; 2,6 e 3,2\% de extrato etéreo e 64,0 e $59,0 \%$ de FDN, para os tratamentos $B C$ e AC, respectivamente. $\mathrm{O}$ aumento do concentrado na dieta influenciou o $\mathrm{pH}$, mas manteve valores que não comprometeram a atividade celulolítica dos

Recibido: 1-9-06. Aceptado: 22-10-08.

\section{AdDITIONAL KEYWORDS}

VFA. Coastcross. Bermuda grass. Cynodon dactylon. Grass dairy production. Ruminant production.

microrganismos ruminais. As concentrações ruminais de $\mathrm{N}-\mathrm{NH}_{3}$ e AGV totais não sofreram alterações com os dois níveis de suplementação com concentrado.

\section{SUMMARY}

Four lactating dairy cows fitted with ruminal cannula were used to study two levels of concentrate supplementation (treatments), low (BC), 2.67 or high (AC), $5.37 \mathrm{~kg}$ of DM/day. Animals were assigned in intermittent grazing Coastcross forage during the summer with a stocking rate of five animal units/hectare. The chemical composition of the concentrate was the same in both treatments and it was divided in equal part to feed the cows at the morning and at the afternoon milking. The aim of this study was to evaluate the ruminal parameters: $\mathrm{pH}$, ammonia nitrogen $\left(\mathrm{N}-\mathrm{NH}_{3}\right)$ concentration and volatile fatty acids (AGV) concentration. The Coastcross had on average $11.7 \%$ of PB, $70.2 \%$ of FDN, $35.2 \%$ of FDA and $63.8 \%$ of in vitro digestibility of dry-matter (DIVMS). The average of dry matter intake was $13.6 \mathrm{~kg}$ and $14.6 \mathrm{~kg}$. The chemical composition of the diets was $13.6 \%$ and $15.2 \%$ of $P B, 2.6 \%$ and 3.2 of EE, $64.0 \%$ and $59.0 \%$ of FDN for $B C$ and $A C$ treatments,

Arch. Zootec. 59 (226): 217-224. 2010. 
MOTA, VILELA, SANTOS, ELYAS, LOPES, VERNEQUE, PAIVA E PINTO NETO

respectively. The increase of the concentrate in diet, influenced rumen $\mathrm{pH}$, however the values not affect cellulose-digesting activity of the rumen microorganisms. The values of $\mathrm{N}-\mathrm{NH}_{3}$ and total AGV of the rumen fluid did not change with the different levels of concentrate.

\section{INTRODUÇÃO}

O uso de pastagens na alimentação de vacas leiteiras resulta em sistema de produção de baixo custo, tendo em vista que o pasto constitui-se no mais barato dos alimentos volumosos para ruminantes (Clark e Kanneganti, 1998; Peyraud e Delaby, 2001; Bargo et al., 2002). Muito se estudou sobre a produção e a digestão de vacas leiteiras em pastagens de clima temperado (Stockdale, 2000; Bargo et al., 2001; Peyraud e Delaby, 2001; Bargo et al., 2002). Todavia, poucos trabalhos foram realizados para avaliação dos parâmetros ruminais de vacas leiteiras em pastagens tropicais, notadamente, $\mathrm{pH}$ e concentrações ruminais de nitrogênio amoniacal $\left(\mathrm{N}-\mathrm{NH}_{3}\right)$ e de ácidos graxos voláteis (AGVs) (Campos et al., 2007). Desta forma, as discussões encontradas em trabalhos realizados no Brasil, seguidamente, fazem comparações àqueles publicados no exterior e, em geral, realizados em pastagens formadas com forrageiras de clima temperado.

A disponibilidade de nitrogênio $(\mathrm{N})$ no rúmen, assim como de outros nutrientes, não deve ser limitante para a fermentação microbiana no rúmen. $\mathrm{O}$ indicador da eficiência de utilização do $\mathrm{N}$ pelo bovino é a concentração de amônia ruminal, visto que cerca de 60 a $80 \%$ do $\mathrm{N}$ incorporado pelos microrganismos advém dela (Satter e Roffler, 1975). A concentração ruminal de $\mathrm{N}_{-} \mathrm{NH}_{3}$ é conseqüência do equilíbrio entre a produção e utilização pelos microrganismos, e esta última depende da quantidade de energia disponível (Borges, 1999).

A proporção relativa dos diferentes AGVs produzidos varia amplamente, dependendo dos componentes químicos degradados e do $\mathrm{pH}$ ruminal. Maior proporção de acetato é produzida na degradação da celulose e hemicelulose, enquanto que com a degradação dos carboidratos solúveis da planta (amido e açúcares), o padrão de produção de AGVs é elevado tanto em propionato, quanto em acetato, e baixo em butirato. Em contrapartida, a degradação de amido de cereais produz alta concentração de propionato. A proporção molar típica dos AGVs produzidos quando o animal alimenta-se basicamente de forragens, representa relação de 73:20:7 (acetato:propionato:butirato), comparado com 60:30:10 em misturas de concentrado e forragens, e somente com concentrado obteve relação 50:40:10 (Black, 1990). Sabe-se que a proporção de $\mathrm{AGV}$ varia também com o tipo de forragem oferecida e seu estádio de maturação (França, 2006).

Mould e Orskov (1984) relataram que dietas, contendo amido, formuladas para ruminantes reduzem a digestão das fibras por vários eventos, dentre estes a preferência dos microrganismos pelos carboidratos não-estruturais, o que leva à redução do $\mathrm{pH}$ ruminal, e por conseqüência a atividade dos microrganismos celulolíticos. Observa-se que moderada redução do $\mathrm{pH}$ (para aproximadamente, 6,2) proporciona exacerbada depressão na digestão da fibra na presença do amido, enquanto que uma severa redução do $\mathrm{pH}$ (valor inferior a 6,0) deprime os microrganismos celulolíticos e limita severamente a digestão da fibra (Shriver et al., 1986). Em pH de 5,8, a quantidade de micróbios associados a partículas de fibra fica reduzida em $43 \%$, quando comparada em pH entre 6,2 e 7,0, observando-se ainda, decréscimo de $15 \%$ no total de microrganismos (Shriver et al., 1986).

Este experimento foi realizado com o objetivo de estudar o efeito de dois níveis de suplementação com concentrado sobre o $\mathrm{pH}$ e as concentrações de amônia e AGVs no rúmen de vacas da raça Holandesa em lactação, manejadas em pastagem de Cynodon dactylon cv. Coastcross no verão. 


\section{MATERIAL E MÉTODOS}

Foram utilizadas quatro vacas da raça Holandesa (puro por cruza, PC), entre 6 a 8 anos, no terço final de lactação, com produção média de 5 a 7 mil litros de leite por lactação, fistuladas no rúmen, com cânulas de borracha de silicone de $10 \mathrm{~cm}$ de diâmetro interno (Bar Diamond ${ }^{\circledR}$ Inc., Parma, Idaho, USA).

Este estudo foi dividido em quatro períodos experimentais, com duração de 17 dias, sendo 16 dias para adaptação dos animais às dietas e um dia para avaliação dos parâmetros ruminais. Após cada período, as quatro vacas portadoras de fistulas ruminais foram redistribuídas, sendo que cada animal participou duplamente de cada tratamento.

As vacas foram mantidas em pastagem de Coastcross (Cynodon dactylon L. Pers. cv. Coastcross), já estabelecida, dividida em quatro blocos de piquetes, sendo cada bloco composto por 40 piquetes, com área unitária de $435 \mathrm{~m}^{2}$. A gramínea foi utilizada com período de pastoreio de, aproximadamente 12 horas, com intervalo de desfolha de 19 dias, e mantendo-se uma taxa de lotação de $5 \mathrm{UA} / \mathrm{ha}$. No manejo da pastagem, adotouse, em média, a altura da forragem de $42 \mathrm{~cm}$ na entrada dos animais e de $19 \mathrm{~cm}$ após o pastejo. O solo da área onde a pastagem foi implantada é classificado como Latossolo Vermelho-Amarelo, e recebeu adubação anual composta de $200 \mathrm{~kg} / \mathrm{ha}$ de nitrogênio, $80 \mathrm{~kg} / \mathrm{ha}$ de $\mathrm{P}_{2} \mathrm{O}_{5}$ e $60 \mathrm{~kg} / \mathrm{ha}$ de $\mathrm{K}_{2} \mathrm{O}$, distribuída em seis aplicações com intervalo de dois meses, realizada a lanço, no dia seguinte ao pastejo.

As vacas foram alimentadas com baixo concentrado (BC) 2,7 ou alto concentrado (AC) $5,4 \mathrm{~kg} /$ dia de matéria seca de concentrado, compondo os dois tratamentos. O concentrado foi dividido em partes iguais, fornecidas no momento das ordenhas da manhã (07 h 00 min) e a da tarde (15 h 00 min), onde se acompanhou seu consumo total. Os ingredientes da suplementação concen- trada e sua quantidade encontram-se na tabela I.

Com intuito de avaliar a quantidade e qualidade da forrageira disponível e determinar os nutrientes ingeridos pelos animais experimentais, realizou-se coletas de amostras da forragem em cada piquete em seu respectivo período experimental, por meio de cortes da forragem a $15 \mathrm{~cm}$ do solo, em uma área útil de um metro quadrado, que foram identificadas, pesadas, embaladas em sacos plásticos e congeladas a $-10^{\circ} \mathrm{C}$. Os períodos experimentais (quatro) foram compreendidos entre os meses de janeiro a março.

Após a coleta, as amostras da forrageira foram congeladas, sendo, posteriormente descongeladas, agrupadas por tratamento $\mathrm{x}$ período, homogeneizadas, pré-secadas em estufa de ventilação forçada $\left(72 \mathrm{~h} ; 55^{\circ} \mathrm{C}\right)$, moídas $(1 \mathrm{~mm})$ e analisadas quanto aos teores de matéria seca (MS), proteína bruta (PB) e fibra em detergente neutro (FDN) e fibra em detergente ácido (FDA), segundo procedimentos descritos por Silva e Queiroz (2002). A digestibilidade in vitro da MS (DIVMS) da pastagem foi determinada segundo procedimento de dois estágios de Tilley e Terry (1963). Paralelamente a este estudo avaliou-se o consumo de MS de 12

Tabela I. Ingredientes e sua quantidade presentes nos suplementos concentrados. (Proportion of the ingredients in concentrates).

\begin{tabular}{|c|c|c|}
\hline \multirow{2}{*}{$\begin{array}{l}\text { Ingredientes } \\
\text { (kg de MS) }\end{array}$} & \multicolumn{2}{|c|}{ Concentrado } \\
\hline & baixo $(\mathrm{BC})$ & alto $(A C)$ \\
\hline Soja integral tostada & 0,935 & 1,869 \\
\hline Milho moído & 1,655 & 3,34 \\
\hline Sal mineral ${ }^{1}$ & 0,0534 & 0,106 \\
\hline Calcário calcítico & 0,026 & 0,053 \\
\hline Concentrado ingerido* & 2,67 & 5,37 \\
\hline
\end{tabular}

${ }^{1}$ Composição do sal mineral= cálcio $90 \mathrm{~g}$, fósforo $70 \mathrm{~g}$, magnésio $80 \mathrm{~g}$, cobre $700 \mathrm{mg}$, zinco $5400 \mathrm{mg}$, cobalto $50 \mathrm{~g}$, iodo $180 \mathrm{~g}$, selênio $40 \mathrm{mg}$, enxofre 20 g, sódio $200 \mathrm{~g}$, manganês $500 \mathrm{mg}$. ${ }^{*} \mathrm{~kg}$ de MS. 
MOTA, VILELA, SANTOS, ELYAS, LOPES, VERNEQUE, PAIVA E PINTO NETO

vacas de cada tratamento, fenotipicamente semelhantes às vacas fistuladas sob as mesmas condições experimentais (Elyas, 2007), pela técnica de fornecimento de cromo segundo metodologia de Kimura e Miller (1957).

O líquido ruminal utilizado para as determinações de $\mathrm{pH}$ e de concentrações de nitrogênio amoniacal $\left(\mathrm{N}-\mathrm{NH}_{3}\right)$ e de ácidos graxos voláteis (AGVs) foi coletado manualmente, através da cânula ruminal, em diferentes tempos de coletas $(0,2,4,6,8,10$, 12 e 24 horas após o primeiro fornecimento diário de concentrado). O líquido ruminal foi filtrado em gaze, sendo imediatamente realizada a medição do $\mathrm{pH}$ (potenciômetro digital marca HANNA ${ }^{\circledR}$ ). Posteriormente, foi extraída alíquota de $5 \mathrm{ml}$, que foi acondicionada e armazenada a $-10^{\circ} \mathrm{C}$, para posterior análise das concentrações de $\mathrm{N}-\mathrm{NH}_{3}$ e AGVs. O acondicionamento das amostras para determinação das concentrações de N$\mathrm{NH}_{3}$ do nitrogênio amoniacal foi realizado em tubos de ensaio $(10 \mathrm{ml})$, onde se adicionaram quatro gotas de ácido sulfúrico $(50 \%)$ e para AGVs também em tubos de ensaio $(10 \mathrm{ml})$, com $1 \mathrm{ml}$ de ácido metafosfórico $(25 \%)$.

O nitrogênio amoniacal (N-NH ${ }_{3}$ ) foi determinado pela destilação de $5 \mathrm{ml}$ de líquido ruminal, em 2,5 g de hidróxido de sódio, utilizando-se ácido bórico como solução receptora e ácido clorídrico $0,01 \mathrm{~N}$ na titulação, conforme descrito em Vieira (1980).

As análises de AGVs foram realizadas com modificações da técnica descrita por Palmquist e Conrad (1971). Foi utilizado cromatógrafo de fase gasosa Agilent modelo $6890 \mathrm{~N}$ (Agilent Technologies Inc., Santa Clara, CA, EUA), dotado de coluna capilar de polietilenoglicol de $30 \mathrm{~m}$ comprimento $\mathrm{x}$ $0,25 \mathrm{~mm}$ diâmetro interno. As condições empregadas no processo de separação cromatográfica foram: temperaturas: $250^{\circ} \mathrm{C}$ para o injetor Split, $100-185^{\circ} \mathrm{C}$ rampa de aquecimento com incremento de $15^{\circ} \mathrm{C} / \mathrm{min}$ para a coluna, $300^{\circ} \mathrm{C}$ detector FID; vazão dos gases: 1,5 ml/min (gás de arraste $\mathrm{H}_{2}$ ), sistema de detecção: $350 \mathrm{ml} / \mathrm{min}$ (ar sintético) e $30 \mathrm{ml} / \mathrm{min}\left(\mathrm{H}_{2}\right), \mathrm{N}_{2} 25 \mathrm{ml} / \mathrm{min}$ (gás saver). $\mathrm{O}$ volume injetado foi de $0,1 \mathrm{ml}$ para as amostras e padrões. O procedimento de quantificação fundamentou no processo em que amostras de calibração e amostras desconhecidas são analisadas sob as mesmas condições. O resultado da amostra desconhecida é comparado com o da amostra-padrão.

Nas análises estatísticas dos dados usou-se o procedimento GLM (General Linear Model) do SAS (1996), por meio de um modelo que incluiu os efeitos fixos de bloco (quatro blocos, formados por duas repetições de área de pastagem (dois piquetes) e duas repetições de animal (duas vacas por piquete) e tratamento (dois), além do efeito aleatório do erro).

\section{RESULTADOSEDISCUSSÃO}

Os efeitos dos diferentes níveis de concentrado sobre os parâmetros ruminais $\mathrm{pH}$ e concentrações de $\mathrm{N}_{-} \mathrm{NH}_{3}$ e de AGVs em seus respectivos tempos de coleta encontram-se na tabela II.

A oferta de $5,4 \mathrm{~kg}$ de concentrado provocou queda do $\mathrm{pH}$ ruminal (tabela II, $\mathrm{p}<0,05$ ), sendo registrados valores médios de 6,75 e 6,64 para a os tratamentos $\mathrm{BC}=2,7$ e $\mathrm{AC}=5,4 \mathrm{~kg}$ de concentrado, respectivamente. Os valores médios de $\mathrm{pH}$, em cada tratamento e nos diferentes tempos de coletas, foram superiores àquele sugerido por Dutra et al. (2004) e Mould e Orskov (1984), de 6,2, para que não haja efeito depressivo do $\mathrm{pH}$ sobre a digestão da fibra alimentar e interferência na população microbiana. $\mathrm{O}$ intervalo de oito horas, entre os fornecimentos de concentrado, aparentemente, permitiu a reestruturação dos mecanismos tamponantes do rúmen, que eleva o $\mathrm{pH}$ após uma queda, após a ingestão do concentrado, segundo relato de Campos et al. (2007). Observou-se concomitantemente que o nível de adubação de $200 \mathrm{~kg} / \mathrm{ha}$ de $\mathrm{N}$ em pastagem de Coastcross, utilizado neste 


\section{PARÂMETROS RUMINAISDEVACASLEITEIRAS}

Tabela II. Efeitos dos tratamentos sobre os parâmetros ruminais. Valores médios encontrados de $\mathrm{pH}, \mathrm{N}-\mathrm{NH}_{3}$ e AGV nos tempos de coleta. (Effect of the treatments on the ruminal parameters. Mean values of $\mathrm{pH}, \mathrm{N}-\mathrm{NH}_{3}$, and $\mathrm{AGV}$ found at the collection times).

\begin{tabular}{|c|c|c|c|c|c|c|c|c|c|}
\hline \multirow[t]{2}{*}{ T } & \multicolumn{3}{|c|}{$\mathrm{pH}$} & \multicolumn{3}{|c|}{$\mathrm{N}-\mathrm{NH}_{3}(\mathrm{mg} / \mathrm{dl})$} & \multicolumn{3}{|c|}{ AGV total $(\mathrm{mMol} / \mathrm{ml})$} \\
\hline & $\mathrm{BC}$ & $A C$ & $p$ & BC & $A C$ & $\mathrm{p}$ & BC & $A C$ & $\mathrm{p}$ \\
\hline 0 & $6,78 \pm 0,05$ & $6,83 \pm 0,05$ & - & $6,52 \pm 0,72$ & $8,15 \pm 0,72$ & -2 & $44,35 \pm 10,33$ & $48,30 \pm 10,33$ & - \\
\hline 2 & $6,77 \pm 0,05$ & $6,74 \pm 0,05$ & - & $9,60 \pm 0,72$ & $10,86 \pm 0,72$ & - & $41,16 \pm 10,33$ & $57,38 \pm 10,33$ & - \\
\hline 4 & $6,88 \pm 0,05$ & $6,69 \pm 0,05$ & - & $9,41 \pm 0,72$ & $9,41 \pm 0,72$ & - & $44,83 \pm 10,33$ & $57,26 \pm 10,33$ & - \\
\hline 6 & $6,68 \pm 0,05$ & $6,60 \pm 0,05$ & - & $7,65 \pm 0,72$ & $6,73 \pm 0,72$ & -4 & $44,92 \pm 10,33$ & $32,49 \pm 10,33$ & - \\
\hline 8 & $6,75 \pm 0,05$ & $6,64 \pm 0,05$ & - & $7,00 \pm 0,72$ & $6,18 \pm 0,72$ & -7 & $72,78 \pm 10,33$ & $35,39 \pm 10,33$ & - \\
\hline 10 & $6,68 \pm 0,05$ & $6,47 \pm 0,05$ & - & $8,40 \pm 0,72$ & $8,30 \pm 0,72$ & -5 & $50,90 \pm 10,33$ & $41,48 \pm 10,33$ & - \\
\hline 12 & $6,71 \pm 0,05$ & $6,59 \pm 0,05$ & - & $8,86 \pm 0,72$ & $8,93 \pm 0,72$ & -2 & $48,81 \pm 10,33$ & $28,56 \pm 10,33$ & - \\
\hline 24 & $6,75 \pm 0,05$ & $6,57 \pm 0,05$ & - & $6,19 \pm 0,72$ & $7,20 \pm 0,72$ & $-\varepsilon$ & $94,60 \pm 10,33$ & $52,12 \pm 10,33$ & - \\
\hline Média & $6,75 \pm 0,05^{\mathrm{a}}$ & $6,64 \pm 0,05^{b}$ & 0,0001 & $7,95 \pm 0,72$ & $8,22 \pm 0,72$ & 0,5 & $55,29 \pm 4,80$ & $44,12 \pm 4,66$ & 0,9 \\
\hline \multicolumn{10}{|c|}{ AGV (mMol/ml) } \\
\hline A & - & - & - & - & - & - & $41,15 \pm 4,04$ & $33,41 \pm 3,93$ & 0,9 \\
\hline$P$ & - & - & - & - & - & - & $8,95 \pm 0,71$ & $6,65 \pm 0,69$ & 0,7 \\
\hline B & - & - & - & - & - & - & $5,18 \pm 0,23$ & $4,05 \pm 0,22$ & 0,9 \\
\hline \multicolumn{10}{|c|}{ AGV (\% do AGV total) } \\
\hline A & - & - & - & - & - & - & 75 & 76 & - \\
\hline $\mathrm{P}$ & - & - & - & - & - & - & 16 & 15 & - \\
\hline B & - & - & - & - & - & - & 9 & 9 & - \\
\hline $\mathrm{A} / \mathrm{P}$ & - & - & - & - & - & - & 4,6 & 5 & - \\
\hline
\end{tabular}

$\mathrm{T}$ : Tempo de coleta (h); A: acetato; $\mathrm{P}$ : proprionato; $\mathrm{B}$ : butirato; $\mathrm{p}=\mathrm{F}$ probabilidade de haver efeito significativo dentre as dietas experimentais; ${ }^{a b}$ médias na linha seguida da mesma letra minúscula não diferem estatisticamente ( $p>0,05)$; $\mathrm{N}^{-N_{3}}$ : nitrogênio amoniacal; $\mathrm{AGV}$ : ácidos graxos voláteis; $\mathrm{BC}$ : vacas suplementadas com 2,67 kg de concentrado; AC: vacas suplementadas com 5,37 kg de concentrado.

experimento, pode ter contribuído com os valores altos de $\mathrm{pH}$, equivalentes aos relatados por Mackle et al. (1996), quando eles aumentaram de 25 para $125 \mathrm{~kg} \mathrm{~N} / \mathrm{ha}$ na adubação das pastagens.

Segundo trabalho de Bargo et al. (2002) a redução significativa $(\mathrm{p}<0,05)$, no valor de $\mathrm{pH}$ ruminal de vacas manejadas sob condição de pastejo e suplementação com concentrado foi obtida somente quando ocorreu o fornecimento de oito $\mathrm{kg} / \mathrm{dia}$ de MS de concentrado, sendo esta quantidade superior à utilizada no tratamento AC. A participação de $64 \%$ de FDN na dieta da BC e 59\% na da AC possibilitou valores superiores a 6,2 para o $\mathrm{pH}$. Granzin e Dryden (2002), trabalhando com uma percentagem de $47 \%$ de FDN, na dieta em MS, obtiveram
pH de 6,13. Tal fato ressalta a relação do FDN com pH ruminal. E que quanto mais fibra efetiva, mais rápido é o aumento do $\mathrm{pH}$ pelo aumento da produção de saliva, movimentos ruminais e liberação dos gases pela eructação.

Neste experimento, os consumos médios de matéria seca e de nutrientes pelos animais experimentais encontram-se na tabela III.

A forrageira apresentou, em média, durante os períodos experimentais, $11,7 \%$ de PB; $70,2 \%$ de FDN; $35,2 \%$ de FDA e $63,7 \%$ de digestibilidade in vitro da matéria seca (DIVMS).

Não se observou diferença $(p>0,05)$ entre os tratamentos para os valores de N-NH (tabela II). Os valores médios observados foram de 7,95 e $8,22 \mathrm{mg} / \mathrm{dl}$ em $\mathrm{BC}$ e $\mathrm{AC}$, 
Tabela III. Valores médios de consumo de matéria seca, nutrientes e composição química da dieta. (Mean values of dry matter intake, nutrient consumption and chemical composition of ration).

\begin{tabular}{lcc}
\hline & \multicolumn{2}{c}{ Consumo $(\mathrm{kg} / \mathrm{dia})$} \\
Tratamentos & $\mathrm{BC}$ & $\mathrm{AC}$ \\
\hline Coastcross (kg MS/ha) & 6725 & 6040 \\
& & \\
MS total (kg) & 13,36 & 14,58 \\
- concentrado & 2,67 & 5,34 \\
- volumoso (pasto) & 10,69 & 9,24 \\
Vol:Con & $80: 20$ & $63: 37$ \\
\% PV & 2,53 & 2,61 \\
DIVMS pasto (\%) & 63,8 & 63,8 \\
& & \\
PB total (kg) & 1,819 & 2,216 \\
- concentrado & 0,566 & 1,133 \\
- volumoso (pasto) & 1,253 & 1,083 \\
\% PB da dieta & 13,60 & 15,20 \\
& & \\
EE total (kg) & 0,349 & 0,468 \\
- concentrado & 0,147 & 0,294 \\
- volumoso (pasto) & 0,202 & 0,174 \\
\% EE da dieta & 2,61 & 3,20 \\
& & \\
FDN total (kg) & 8,561 & 8,596 \\
- concentrado & 1,053 & 2,106 \\
- volumoso (pasto) & 7,508 & 6,490 \\
\% FDN da dieta & 64,00 & 59,00 \\
\hline BC: baixo concentrado; AC: & alto concentrado \\
\hline
\end{tabular}

respectivamente. $\mathrm{O} \mathrm{N}-\mathrm{NH}_{3}$ observado foi superior a $5 \mathrm{mg} / \mathrm{dl}$, que segundo Satter e Slyter (1974), seria a concentração mínima necessária para permitir uma adequada fermentação bacteriana no rúmen.

As concentrações de $\mathrm{N}-\mathrm{NH}_{3}$ diferiram, com um aumento, entre os tratamentos duas horas do fornecimento do concentrado na primeira ordenha $(p<0,05)$. Esse aumento está relacionado com a maior ingestão de $\mathrm{PB}$, principalmente pelos animais do tratamento AC (tabela II), ressaltando, maior degradabilidade da proteína contida no suplemento em relação à proteína da pastagem. Dados semelhantes foram relata- dos por Delagarde et al. (1997) ao compararem o fornecimento de farelo de soja e dietas exclusivas a pasto, e por Bargo et al. (2001), que forneceu 6,3 kg MS/dia de dietas concentradas com 15 e $23 \%$ de PB.

As menores concentrações de $\mathrm{N}-\mathrm{NH}_{3}$ no líquido ruminal em relação ao tempo de coleta observada na tabela II, pode estar associada à utilização deste nitrogênio (N$\mathrm{NH}_{3}$ ) para a síntese de proteína e/ou absorção ruminal.

As concentrações médias de AGVt (AGVs total) do líquido ruminal foram semelhantes entre os tratamentos (tabela II, $\mathrm{p}>0,05), 55,29 \mathrm{mMol} / \mathrm{ml} \mathrm{em} \mathrm{BCe} 44,12 \mathrm{mMol} /$ $\mathrm{ml}$ em AC. Os valores obtidos no tratamento AC para ácidos acético, propiônico, butírico e AGVt foram inferiores aos encontrados por Alvarez et al. (2001) quando trabalharam com quantidade próxima de concentrado, chegando a 90,6;49,5;24,3 e 12,2 mMol/ml para AGVt, acetato, propionato e butirato, respectivamente. Tal diferença pode estar relacionada à utilização de forrageira de clima temperado (Avena sativa), sendo esta de maior digestibilidade e valor nutricional. As concentrações de AGVs destes experimentos foram próximas às encontradas por Soares (2002) quando forneceu, capim-elefante suplementado com dois ou quatro $\mathrm{kg} /$ vaca/dia de concentrados, sendo 59, $1 ; 38,7$; 13,9 e $6,4 \mathrm{mMol} / \mathrm{ml}$ para $\mathrm{AGVt}$, acetato, proprionato e butirato. Segundo Ítavo et al. (2000), as concentrações de AGVs total ou individual no rúmen são altamente variáveis e dependem da freqüência de alimentação, tempo após a alimentação e composição da dieta. Além disso, o pH do fluído ruminal pode influenciar bactérias produtoras de AGVs específicos.

No presente experimento, foi obtida uma proporção relativa dos AGVs produzidos próxima do proposto por Black (1990) quando os animais receberam basicamente forragens. As proporções relativas obtidas para BC $(75: 16: 9)$ e AC $(76: 15: 9)$ foram semelhantes. A adição de $2,7 \mathrm{~kg}$ de MS de concentrado no tratamento $\mathrm{AC}$, levando à 


\section{PARÂMETROS RUMINAIS DE VACASLEITEIRAS}

proporção volumoso:concentrado de 63:37 na dieta, não afetou a proporção de $\mathrm{AGV}$ produzidos pela microbiota ruminal de vacas da raça Holandesa em pastagem de Coastcross fertilizada.

A concentração de gordura no leite foi semelhante entre BC e AC. A maior concentração de acetato favorece a síntese de gordura, mas, neste experimento, não houve diferença entre a concentração absoluta de acetato $(p>0,05)$ e entre as proporções de AGV das dietas testadas.

\section{CONCLUSÃO}

$\mathrm{O}$ aumento da quantidade de concentrado na dieta influenciou o $\mathrm{pH}$ ruminal, mas manteve valores que não comprometeram a

\section{BIBLIOGRAFIA}

Alvarez, H.J., Santini, F.J., Rearte, D.H. and Elizalde, J.C. 2001. Milk production and ruminal digestion in lactating dairy cows grazing temperate pastures and supplemented with dry cracked corn or high moisture corn. Anim. Feed Sci. Technol., 91: 183-195.

Bargo, F., Rearte, D.H., Santini, F.J. and Muller, L.D. 2001. Ruminal digestion by dairy cows grazing winter oats pasture supplemented with different levels and sources of protein. J. Dairy Sci., 84: 2260-2272.

Bargo, F., Muller, L.D.J.E., Delahoy, J.E. and Cassidy, T.W. 2002. Milk response to concentrate supplementation of high producing dairy cows grazing at two pasture allowances. J. Dairy Sci., 85: 1777-1792.

Black, J.L. 1990. Nutrition of the grazing ruminant. Proc. New Zel. Soc. Prod., 50: 07-27.

Borges, A.L.C.C. 1999. Controle da ingestão de alimentos. Cad. Técn. Esc. Vet. UFMG, 21:6769.

Campos, W.E., Benedetti, N.M., Rodrígues Saliba, E.S., Borges, A.L.C.C., Lachica, M. y Lopez, M 2007. Cinética ruminal de vacas leiteiras a pasto consumindo diferentes gramíneas tropicais Arch. Zootec., 56: 829-837.

Clark, D.A. and Kanneganti, V.R. 1998. Grazing management system for dairy cattle. In: Cherney, J.H. and Cherney, D.J.R. (eds.). Grass for Dairy atividade celulolítica dos microrganismos ruminais. Os valores de $\mathrm{N}-\mathrm{NH}_{3}$ e AGV do líquido ruminal não sofreram alterações com o aumento de 2,7 para 5,4 na quantidade diária fornecida da suplementação de concentrado.

\section{AGRADECIMENTOS}

Os autores agradecem à Embrapa Gado de Leite e seus técnicos pelo apoio no trabalho de campo e nas análises laboratoriais. A CAPES pela concessão da bolsa de estudos ao primeiro autor. Ao $\mathrm{CNPq}$, Embrapa Gado de Leite e Programa de PósGraduação em Zootecnia (PPZ) da Universidade Estadual de Maringá pelo auxílio financeiro ao projeto.

Cattle. CAB Int. Oxon, UK. 331 pp.

Delagarde, R., Peyrauld, J.L. and Delaby, L. 1997. The effect of nitrogen fertilization level and protein supplementation on herbage intake, feeding behaviour and digestion in grazing dairy cows. Anim. Feed Sci. Tech., 66: 165-180.

Dutra, A.R., Queiroz, A.C., Thiébaut, J.T.L., Dutra, L.G., Wascheck, R.C. e Moreira, P.C. 2004. Efeitos dos níveis de fibra e de fontes de proteínas sobre a concentração do nitrogênio amoniacal e pH ruminal em novilhos. Rev. Bras. Zootecn., 33: 714-722.

Elyas, A.C.W. 2007. Consumo de matéria seca e produção de leite de vacas "Holandês" manejadas sob pastejo e utilização do modelo Cornell net carbohydrate and protein system. Tese Doutorado. Universidade Federal de Lavras. Lavras-MG. 147 pp.

França, S.R.A. 2006. Perfil dos produtores, características das propriedades e qualidade do leite bovino nos municípios de Esmeraldas e Sete Lagoas, MG. Tese Doutorado. Escola de Veterinária da Universidade Federal de Minas Gerais. Belo Horizonte, MG. 112 pp.

Granzin, B.C. and Dryden, G.M. 2002. The effects of level of dietary protein on the milk production and rumen physiology of dairy cows fed a diet based on tropical grass hay. Trop. Grass., 36: 239-247.

Archivos de zootecnia vol. 59, núm. 226, p. 223. 


\section{MOTA, VILELA, SANTOS, ELYAS, LOPES, VERNEQUE, PAIVA E PINTO NETO}

Ítavo, L.C.V., Santos, G.T., Jobim, C.C., Voltolini, T.V.e Ferreira, C.C. 2000. Avaliação da silagem de bagaço de laranja com diferentes aditivos por intermédio dos parâmetros de fermentação ruminal de ovinos e contribuição energética dos ácidos graxos voláteis. Rev. Bras. Zootecn., 29: 1491-1497.

Kimura, F.T. and Miller, V.L. 1957. Chromic oxide measurement. Improved determination of chromic oxide in cow feed and feces. J. Agr. Food Chem., 5: 216-232.

Mackle, T.R., Bryant, A.M. and Parr, C.R. 1996. Nitrogen fertilizer effects on milk yield and composition, pasture intake, nitrogen and energy partitioning, and rumen fermentation parameters of dairy cows in early lactation. New Zeal. J. Agr. Res., 39: 341-356.

Mould, F.L. and Orskov, E.R. 1984. Manipulation of rumen fenid $\mathrm{pH}$ and influence on cellulose in sacco, dry matter degradation and the run microflora of sheep offered either hay or concentrate. Anim. Feed Sci. Tech., 10: 1-14. Palmquist, D. and Conrad, H. 1971. Origin of plasma fatty acids in lactating cows fed high fat diets. J. Dairy Sci., 54: 1025.

Peyraud, J.L.and Delaby, L. 2001. Ideal concentrate feeds for grazing dairy cows. Responses to supplementation in interaction with grazing management and grass quality. In: Garnsworthy, P.C. and J. Wiseman (eds.). Recent advances in Animal Nutrition. Nottingham University Press. Nottingham, UK. pp: 203-220.
Satter, L.D. and Roffler, R.E. 1975. Nitrogen requirement and utilization in dairy cattle. $J$. Dairy Sci., 58: 1219-1237.

Satter, L.D. and Slyter, L.L. 1974. Effect of ammonia concentration on rumen microbial protein production in vitro. Brit. J. Nutr., 32: 199-205.

Shriver, B.J., Hoover, W.H., Sargent, J.P., Crawford Jr., R.J. and Thayne, W.V. 1986. Fermentation of a high concentrate diet as affected by ruminal pH and digesta flow. J. Dairy Sci., 69: 413-419.

Silva, J.S. e Queiroz, A.C. 2002. Análise de alimentos: métodos químicos e biológicos. $3^{\mathrm{a}}$ ed. UFV. Viçosa. $235 \mathrm{pp}$.

Soares, J.P.G. 2002. Fatores limitantes do consumo de capim-elefante cv. Napier utilizando vacas leiteiras confinadas. Tese Doutorado. Universidade Estadual Paulista. Jaboticabal, SP. $110 \mathrm{pp}$.

SAS. 1996. Statistical analysis systems. User's guide: statistics, version 6.11. SAS Institute. Cary, NC.

Stockdale, C.R. 2000. Levels of pasture substitution when concentrates are fed to grazing dairy cows in northern Victoria. Aust. J. Exp. Agr., 40: 913-921.

Tilley, J.M.A. and Terry, R.A. 1963. A two-stage technique for the in vitro digestion of forage crops. J. Brit. Grass. Soc., 18: 104-111.

Vieira, P.F. 1980. Efeito do formaldeído na proteção de proteínas e lipídios em rações para ruminantes. Tese Doutorado. Universidade Federal de Viçosa. Viçosa, MG. 98 pp. 